\title{
A COMPARATIVE STUDY OF HAEMODYNAMIC RESPONSES TO LARYNGOSCOPY AND ENDOTRACHEAL INTUBATION WITH DIRECT LARYNGOSCOPE AND VIDEO LARYNGOSCOPE IN PATIENTS POSTED FOR CORONARY ARTERY BYPASS GRAFTING
}

\author{
Tapas Kumar Barman1, Kakali Ghosh², Chaitali Sen³, Anupam Goswami4 \\ ${ }_{1}^{1}$ Postgraduate Trainee, Department of Anaesthesiology, IPGME \& R, Kolkata. \\ ${ }^{2}$ Assistant Professor, Department of Cardiac Anaesthesiology, IPGME \& R, Kolkata. \\ 3 Professor, Department of Cardiac Anaesthesiology, IPGME \& R, Kolkata. \\ ${ }^{4}$ Professor, Department of Cardiac Anaesthesiology, IPGME \& R, Kolkata.
}

\begin{abstract}
BACKGROUND

Laryngoscopy and endotracheal intubation is associated with haemodynamic changes which may have detrimental effects in patients with significant coronary artery disease. Video laryngoscope is a type of indirect laryngoscope which causes less stretching of oropharyngeal tissues, so can cause lesser haemodynamic changes than direct laryngoscope using Macintosh blade.

The aim of the present study was to assess the haemodynamic responses to laryngoscopy and endotracheal intubation with Macintosh Direct Laryngoscope and The King Vision ${ }^{\circledR}$ Video Laryngoscope (primary outcome) and also to assess the intubation time and complications if any (secondary outcomes).
\end{abstract}

\section{MATERIALS AND METHODS}

Total seventy patients with significant coronary artery disease scheduled for elective coronary artery bypass grafting surgery were randomly allocated to Group I (Macintosh direct laryngoscope, $n=35$ ) and Group II (The King Vision® video laryngoscope, $n=35$ ) by computer generated random number table. Time taken for intubation and haemodynamic changes (heart rate, systolic blood pressure, diastolic blood pressure, mean arterial pressure) associated at different time intervals were noted.

\section{RESULTS}

There was no significant difference $(\mathrm{p}=0.631)$ in time taken for intubation between Group I (23.57 $\pm 5.34 \mathrm{~s})$ and Group II $(22.94 \pm 5.56 \mathrm{~s})$. With respect to the haemodynamic changes there was no significant difference in heart rate between two Groups. But the changes in systolic blood pressure, diastolic blood pressure and mean arterial pressure were significantly lower in Group I compared to Group II at 40 sec., 50 sec., 1 min. and 2 min. interval of post-intubation period $(\mathrm{p}<0.05)$.

\section{CONCLUSION}

The King Vision ${ }^{\circledR}$ video laryngoscope causes lesser haemodynamic responses following laryngoscopy and endotracheal intubation compared to Macintosh direct laryngoscope in patients having coronary artery disease.

\section{KEYWORDS}

Video Laryngoscope, Direct Laryngoscope, Haemodynamic Responses, Coronary Artery Bypass Grafting.

HOW TO CITE THIS ARTICLE: Barman TK, Ghosh K, Sen C, et al. A comparative study of haemodynamic responses to laryngoscopy and endotracheal intubation with direct laryngoscope and video laryngoscope in patients posted for coronary artery bypass grafting. J. Evolution Med. Dent. Sci. 2017;6(16):1248-1252, DOI: 10.14260/Jemds/2017/271

\section{BACKGROUND}

Laryngoscopy and endotracheal intubation is one of the vital steps during general anaesthesia. It has been observed that laryngoscopy and endotracheal intubation causes reflex sympathetic responses leading to untoward effects in cardiovascular system, of which tachycardia and hypertension are notable. In healthy patients, these exaggerated haemodynamic responses are often well tolerated. However, when these haemodynamic responses become significant, they can result in myocardial ischaemia in patients with coronary artery disease which may alter the balance between myocardial oxygen supply and demand. A variety of factors are associated with these stress responses

Financial or Other, Competing Interest: None.

Submission 18-01-2017, Peer Review 11-01-2017,

Acceptance 17-02-2017, Published 23-02-2017.

Corresponding Author:

Kakali Ghosh,

Assistant Professor,

Department of Cardiac Anaesthesiology,

IPGME \& R, \#83, Dum Dum Park, Kolkata-700055.

E-mail: gkakali354@gmail.com

DOI: $10.14260 /$ jemds $/ 2017 / 271$

\section{(c) $(1)(5)$}

and various methods (both pharmacological and nonpharmacological) have been studied and utilised over the years to attenuate these haemodynamic responses to laryngoscopy and endotracheal intubation.

Direct laryngoscopy with Macintosh blade involves stretching of oropharyngeal tissues in an attempt to straighten the angle between mouth and glottic opening.[1] This stress can cause pain and thereby triggers the stress responses.[1] Since tracheal intubation is unavoidable for surgeries like coronary artery bypass grafting, the attempt to reduce sympathetic stimulation is now directed towards minimising the stretching of tissues in the laryngopharynx. ${ }^{[1]}$ Video laryngoscope is a type of indirect laryngoscope designed for difficult intubation as well as routine intubation. Video laryngoscopes have consistently resulted in superior laryngeal view, reduced the need for optimisation manoeuvres and reduced intubation difficulty scores as compared with Macintosh Direct Laryngoscope (MDL).[2] The King Vision ${ }^{\circledR}$ Video Laryngoscope(KVL) allows the operator to visualise the virtual image of patient's vocal cord indirectly without obtaining the direct line of sight. It is a portable, battery operated, rigid, digital video laryngoscope ${ }^{[3]}$ system that incorporates an integrated reusable display and choice of 
disposable blades designed to visualise the airway while aiding in the placement of airway devices. The disposable component of the KVL consists of two types of disposable or reusable blade. One is channelled blade, another is nonchannelled standard blade.[3] The channelled blade incorporates a guiding channel to facilitate delivery of an endotracheal tube to vocal cord. The angulation of the channelled blade is made in such a way that it needs much less alignment of oral, pharyngeal and laryngeal axis for visualisation of the glottis and tracheal intubation. So there is minimal oropharyngolaryngeal stimulation and may hence potentially attenuate the stress responses. We hypothesised that the use of the KVL would attenuate the haemodynamic responses to laryngoscopy and tracheal intubation as compared with the MDL. The aim of the present study was to assess the haemodynamic responses to laryngoscopy and endotracheal intubation with Macintosh Direct Laryngoscope and The King Vision $₫$ Video Laryngoscope (primary outcome) and also to assess the intubation time and complications if any (secondary outcomes).

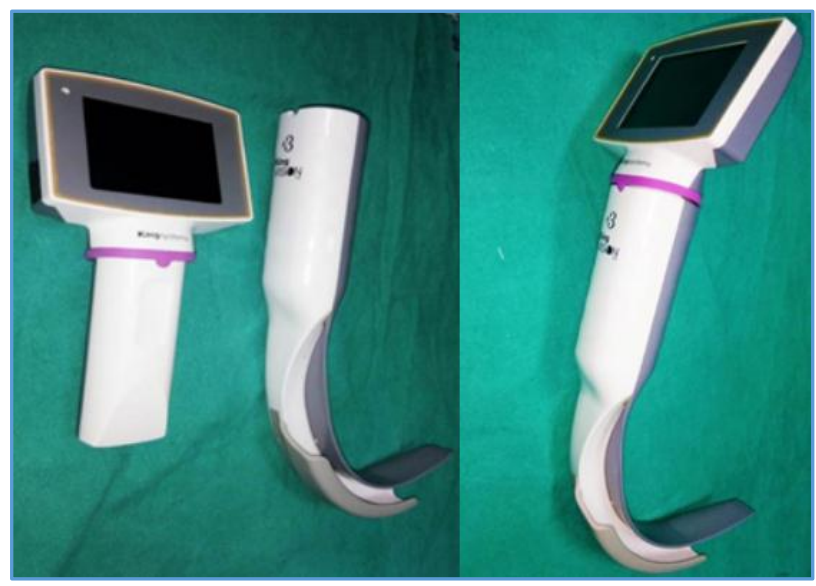

The King Vision ${ }^{\circledR}$ Video Laryngoscope with channelled Blade

\section{MATERIALS AND METHODS}

After getting approval from the Institutional Ethical Committee and written informed consent, total 70 patients were selected of the age group between 35 to 65 years, belonging to NYHA I \& II and Mallampati score I, II for this study who were scheduled for elective primary coronary artery bypass grafting (CABG) surgery. It was a prospective, single blinded, randomised control study. Patients with NYHA III \& IV, ejection fraction $<30 \%$, diabetes, renal disease, hepatic disease, neurological diseases, severe respiratory disease, anticipated difficult intubation (Mallampati III \& IV, thyromental distance $<6 \mathrm{~cm}$, interincisor gap $<3 \mathrm{~cm}$ ), oral pathology or mass, history of relevant drug allergy, risk of gastric aspiration, any bleeding diathesis, permanent pacemaker, who refused to give consent and underwent emergency coronary artery bypass grafting were excluded from this study.

The sample size was calculated on the basis of difference in mean arterial pressure in immediate post-intubation period as primary outcome measure. It is estimated that 35 subjects would be required per Group in order to detect the difference of $10 \mathrm{~mm}$ of $\mathrm{Hg}$ in mean arterial pressure with $80 \%$ power and $5 \%$ possibility of type I error. This calculation assumes standard deviation of $15 \mathrm{~mm}$ of $\mathrm{Hg}$ for these parameters in two sided testing. Total 70 patients divided randomly by computer generated random number table into two Groups (Group I, n=35 and Group II, n=35).

All patients were maintained in fasting state for about 68 hours and received premedication of tablet diazepam (10 $\mathrm{mg}$ ) orally on previous night of surgery. Standard monitoring included were 12-lead electrocardiogram (ECG), invasive blood pressure, peripheral capillary oxygen saturation $\left(\mathrm{SpO}_{2}\right)$, end tidal carbon dioxide $\left(\mathrm{EtCO}_{2}\right)$, core body temperature. Baseline parameters were recorded 15 minutes before induction. A wide bore intravenous cannula and an invasive arterial line were inserted under local anaesthesia prior to induction of general anaesthesia.

All patients were pre-oxygenated with $100 \%$ oxygen for 3 min. Induction was done using injection fentanyl IV @ 4-5 $\mu \mathrm{g} / \mathrm{kg}$ body weight, injection midazolam IV @ 0.1- $0.2 \mathrm{mg} / \mathrm{kg}$ and injection thiopentone sodium intravenously @ 4-6 mg/kg slowly in titrated doses till the eyelash reflexes disappear, followed by injection rocuronium intravenously at $0.9 \mathrm{mg} / \mathrm{kg}$ body weight.

After giving muscle relaxant, all patients were manually ventilated and intubated after 90 seconds. Tracheal intubation done with MDL (Blade size 3 for female, size 4 for male) were included in Group I and tracheal intubation done with KVL (Channelled blade size 3 for both sexes) included in Group II. Correct placement of endotracheal tube was confirmed by auscultation over chest and $\mathrm{EtCO}_{2}$ level. The endotracheal tube was connected to the breathing circuit and controlled ventilation was given with the help of ventilator with the aim to maintain $\mathrm{EtCO}_{2}$ between $30-40 \mathrm{~mm}$ of $\mathrm{Hg}$ and $\mathrm{SpO}_{2}$ above $95 \%$. All laryngoscopies were performed by the same anaesthesiologist having experience of using both types of laryngoscope. The time taken for intubation was calculated from the time of picking of laryngoscope to the time the blade was removed from the mouth after successful intubation using a stop watch. Parameters collected were heart rate (HR), systolic blood pressure (SBP), diastolic blood pressure (DBP), mean arterial pressure(MAP), electrocardiogram (ECG), peripheral capillary oxygen saturation $\left(\mathrm{SpO}_{2}\right)$, end tidal carbon dioxide level $\left(\mathrm{EtCO}_{2}\right)$. The above-mentioned parameters were noted at the following stages in both the Groups: At baseline (15 minutes before induction), just before laryngoscopy, after intubation every 10 seconds for one minute, then on $2^{\text {nd }}, 3^{\text {rh }}, 4^{\text {th }}, 5^{\text {th }}$ and $10^{\text {th }}$ minute. Use of stylet or bougie, requirement of any other drugs, number of unsuccessful attempts, optimal laryngeal external manipulation (OLEM) ${ }^{[2]}$ during intubation and any adverse outcome were also noted.

\section{Statistical Analysis}

Data were summarised by routine descriptive statistics, namely mean \& standard deviation for numerical variables and counts \& percentages for categorical variable. Numerical variables were compared between the Groups by Student's Independent Sample $t$ test if normally distributed or by Mann-Whitney U test if otherwise. Chi-square test or Fisher's exact test would be employed for intergroup comparison of categorical variables. Changes in numerical variables over time within a Group were assessed for statistical significance by repeated measures, ANOVA followed by Tukey's test for comparison between two individual time points. Testing would be two sided and $\mathrm{p}<0.05$ was considered statistically significant. 


\section{RESULTS}

All the 70 patients completed the study and all patients were intubated in a single attempt. In terms of demographic profile, both groups' patients were almost similar (Table 1). Both groups were comparable with respect to baseline characteristics data. Time taken for intubations (Table 2) were little bit lower with video laryngoscope (Gr II) (22.94 \pm 5.56$)$ compared to direct laryngoscope (Gr I) (23.57 \pm 5.34$)(p=0.631)$. No adverse outcomes were noted.

\begin{tabular}{|c|c|c|c|}
\hline Parameter & Group I & Group II & P value \\
\hline $\begin{array}{l}\text { Age (Years) } \\
\text { (MEAN } \pm \text { SD) }\end{array}$ & $53.20 \pm 6.30$ & $55.69 \pm 5.98$ & 0.095 \\
\hline Sex (Male/Female) & $28 / 7$ & $29 / 6$ & 1.000 \\
\hline $\begin{array}{l}\text { Body Weight (KG) } \\
\text { (MEAN } \pm S D)\end{array}$ & $60.80 \pm 7.53$ & $58.23 \pm 5.64$ & 0.111 \\
\hline $\begin{array}{l}\text { Height }(\mathrm{CM}) \\
(\mathrm{MEAN} \pm \mathrm{SD})\end{array}$ & $163.89 \pm 6.47$ & $163.26 \pm 5.21$ & 0.656 \\
\hline Mallampati (I/II) & $4 / 31$ & $2 / 33$ & 0.434 \\
\hline NYHA (I/II) & $32 / 3$ & $29 / 6$ & 0.477 \\
\hline \multicolumn{4}{|c|}{ Table 1. Patients Demographic and other Profile } \\
\hline
\end{tabular}

\begin{tabular}{|c|c|c|}
\hline Group & $\begin{array}{c}\text { Time Taken for } \\
\text { Intubation (Sec) }\end{array}$ & P value \\
\hline (MEAN \pm SD) & \\
\hline Gr I & $23.57 \pm 5.34$ & 0.631 \\
\hline \multicolumn{2}{|c|}{ Table 2. Comparison of Time taken for Intubation } \\
between the Study Population
\end{tabular}

The baseline heart rate (HR), systolic blood pressure (SBP), diastolic blood pressure (DBP) and mean arterial pressures (MAP) were similar in both groups. After induction of anaesthesia and before laryngoscopy (BL), a significant reduction in SBP, DBP and MAP were recorded in both groups from their baseline values while HR change was not significant. Immediately before laryngoscopy, there was no significant difference between the two groups ( $\mathrm{p}$-values > 0.05). Immediately after intubation, there was significant increase in HR (Table 3) in both groups; however, there was no significant difference between the groups $(\mathrm{p}>0.05)$. The increase in heart rate gradually returned to baseline by $3 \mathrm{~min}$. in both groups. After intubation, SBP, DBP and MAP were increased significantly in both the groups. But changes in systolic blood pressure (Table 4), diastolic blood pressure (Table 5) and mean arterial pressure (Table 6) were significantly lower $(p<0.05)$ in Group II patients compared to Group I patients at 40 seconds, 50 seconds, 1 minute and 2 minutes time interval after intubation. Rest of the time interval there was no significant differences in haemodynamic responses between two Groups. The SBP, DBP and MAP returned to baseline value by 3 minutes in both the groups.

\begin{tabular}{|c|c|c|c|}
\hline TIME & Group I & Group II & $\begin{array}{c}\text { P } \\
\text { Value }\end{array}$ \\
\hline Baseline & $79.17 \pm 10.82$ & $80.66 \pm 9.27$ & 0.539 \\
\hline Before Laryngoscopy & $83.51 \pm 10.48$ & $86.94 \pm 8.94$ & 0.146 \\
\hline 10 sec. After Intubation & $93.11 \pm 10.92$ & $97.74 \pm 9.92$ & 0.068 \\
\hline 20 sec. After Intubation & $103.26 \pm 11.30$ & $105.43 \pm 9.56$ & 0.389 \\
\hline 30 sec. After Intubation & $109.14 \pm 11.32$ & $107.09 \pm 9.49$ & 0.413 \\
\hline 40 sec. After Intubation & $110.23 \pm 10.11$ & $106.06 \pm 9.19$ & 0.075 \\
\hline 50 sec. After Intubation & $108.23 \pm 9.70$ & $105.03 \pm 9.58$ & 0.169 \\
\hline
\end{tabular}

\begin{tabular}{|l|c|c|c|}
\hline 1 min. After Intubation & $106.57 \pm 9.44$ & $102.94 \pm 9.07$ & 0.106 \\
\hline 2 min. After Intubation & $93.63 \pm 10.24$ & $92.83 \pm 9.57$ & 0.737 \\
\hline 3 min. After Intubation & $87.43 \pm 9.52$ & $88.14 \pm 9.51$ & 0.754 \\
\hline 4 min. After Intubation & $84.49 \pm 8.96$ & $86.71 \pm 8.82$ & 0.298 \\
\hline 5 min. After Intubation & $84.43 \pm 9.11$ & $84.31 \pm 9.02$ & 0.958 \\
\hline 10 min. After Intubation & $81 \pm 10.84$ & $78.31 \pm 8.74$ & 0.258 \\
\hline
\end{tabular}

Table 3. Heart Rate at Baseline, before Laryngoscopy (BL) and after Intubation

\begin{tabular}{|c|c|c|c|}
\hline TIME & Group I & Group II & $P$ Value \\
\hline Baseline & $150.77 \pm 15.72$ & $146.40 \pm 14.56$ & 0.232 \\
\hline $\begin{array}{c}\text { Before } \\
\text { Laryngoscopy }\end{array}$ & $112.40 \pm 13.72$ & $107.86 \pm 10.50$ & 0.124 \\
\hline 10 sec. After Intubation & $122.8 \pm 12.85$ & $121.5 \pm 11.14$ & 0.656 \\
\hline 20 sec. After Intubation & $135.4 \pm 10.69$ & $136.34 \pm 11.458$ & 0.737 \\
\hline 30 sec. After Intubation & $147.4 \pm 9.98$ & $142.34 \pm 11.66$ & 0.055 \\
\hline 40 sec. After Intubation & $161.1 \pm 9.59$ & $142.54 \pm 11.88$ & 0.0001 \\
\hline 50 sec. After Intubation & $162 \pm 10.64$ & $140.49 \pm 11.96$ & 0.0001 \\
\hline 1 min. After Intubation & $158.7 \pm 10.87$ & $137.74 \pm 11.98$ & 0.0001 \\
\hline 2 min. After Intubation & $129.8 \pm 11.2$ & $122.43 \pm 12.66$ & 0.0118 \\
\hline 3 min. After Intubation & $115.4 \pm 8.75$ & $113 \pm 9.95$ & 0.293 \\
\hline 4 min. After Intubation & $112 \pm 6.27$ & $110.03 \pm 8.31$ & 0.266 \\
\hline 5 min. After Intubation & $110.3 \pm 5.49$ & $108.54 \pm 6.96$ & 0.249 \\
\hline 10 min. After Intubation & $114 \pm 6.78$ & $116.69 \pm 7.01$ & 0.112 \\
\hline
\end{tabular}

\begin{tabular}{|c|c|c|c|}
\hline Time & Group I & Group II & P Value \\
\hline Baseline & $83.37 \pm 11.35$ & $80.20 \pm 10.82$ & 0.246 \\
\hline Before Laryngoscopy & $66.91 \pm 11.52$ & $66 \pm 9.67$ & 0.720 \\
\hline 10 sec. After Intubation & $72.91 \pm 9.79$ & $72.43 \pm 9.204$ & 0.831 \\
\hline 20 sec. After Intubation & $78.91 \pm 8.67$ & $79.17 \pm 8.375$ & 0.900 \\
\hline 30 sec. After Intubation & $84.54 \pm 7.84$ & $82.14 \pm 8.51$ & 0.224 \\
\hline 40 sec. After Intubation & $92.54 \pm 6.67$ & $82.29 \pm 8.78$ & 0.0001 \\
\hline 50 sec. After Intubation & $94 \pm 7.02$ & $81.17 \pm 8.86$ & 0.0001 \\
\hline 1 min. After Intubation & $92.43 \pm 6.86$ & $79.14 \pm 8.46$ & 0.0001 \\
\hline 2 min. After Intubation & $75.43 \pm 7.56$ & $71.57 \pm 7.81$ & 0.039 \\
\hline 3 min. After Intubation & $69.29 \pm 7.01$ & $66.49 \pm 6.43$ & 0.086 \\
\hline 4 min. After Intubation & $66.17 \pm 5.12$ & $64.57 \pm 5.55$ & 0.214 \\
\hline 5 min. After Intubation & $64.17 \pm 4.26$ & $63.54 \pm 5.62$ & 0.599 \\
\hline 10 min. After Intubation & $66.17 \pm 5.17$ & $68.03 \pm 6.55$ & 0.192 \\
\hline
\end{tabular}

Table 5. Diastolic Blood Pressure at Baseline, before Laryngoscopy (BL) and after Intubation

\begin{tabular}{|c|c|c|c|}
\hline Time & Group I & Group II & P Value \\
\hline Baseline & $105.84 \pm 12.68$ & $102.27 \pm 11.69$ & 0.225 \\
\hline Before laryngoscopy & $82.08 \pm 11.76$ & $79.95 \pm 9.72$ & 0.413 \\
\hline 10 sec. After Intubation & $89.54 \pm 10.38$ & $88.80 \pm 9.57$ & 0.766 \\
\hline 20 sec. After intubation & $97.77 \pm 9.04$ & $98.23 \pm 8.93$ & 0.843 \\
\hline 30 sec. After intubation & $105.5 \pm 8.32$ & $102.21 \pm 9.07$ & 0.123 \\
\hline 40 sec. After Intubation & $115.4 \pm 7.44$ & $102.37 \pm 9.27$ & 0.0001 \\
\hline 50 sec. After Intubation & $116.7 \pm 8.12$ & $11.94 \pm 9.33$ & 0.0001 \\
\hline 1 min. After Intubation & $114.5 \pm 8.02$ & $98.68 \pm 8.89$ & 0.0001 \\
\hline 2 min. After Intubation & $93.57 \pm 8.65$ & $88.52 \pm 8.85$ & 0.017 \\
\hline 3 min. After Intubation & $84.63 \pm 7.21$ & $81.99 \pm 7.21$ & 0.133 \\
\hline 4 min. After Intubation & $81.43 \pm 5.14$ & $79.72 \pm 6.12$ & 0.225 \\
\hline 5 min. After Intubation & $79.6 \pm 4.35$ & $78.54 \pm 5.88$ & 0.409 \\
\hline 10 min. After Intubation & $82.11 \pm 5.52$ & $84.25 \pm 6.38$ & 0.142 \\
\hline
\end{tabular}

Table 6. Mean Arterial Pressure at Baseline, before Laryngoscopy (BL) and after Intubation 


\section{DISCUSSION}

Laryngoscopy and endotracheal intubation is associated with significant haemodynamic changes especially in patients having coronary artery disease. The magnitude of haemodynamic response is directly related to the force \& duration of laryngoscopy.[1] Although these changes are usually transient they can be dangerous in susceptible patients resulting in morbidity and mortality and can be detrimental in patients with cardiovascular disease. ${ }^{[4,5]}$ Pharmacologic interventions might depress the cardiovascular system resulting in undesired hypotension and bradycardia.[6] Increasing the depth of anaesthesia can blunt these deleterious effects; however, changes in the concentration of anaesthetic agents in blood occur slowly in relation to the onset and offset of airway stimuli and haemodynamic responses. $[7,8,9]$ So the haemodynamic changes may be reduced by minimising the force and duration of laryngoscopy so that the adverse effects of pharmacological agents can be avoided.

In our study, we have found significantly less haemodynamic changes with KVL compared to MDL in terms of SBP, DBP and MAP. There were significant changes in haemodynamic parameters during the post-intubation period in both the groups. But KVL was associated with less significant rise of SBP, DBP and MAP compared to MDL. Rise in HR was not significant between the two groups.

Dashti $\mathrm{M}$ et al[7] et al conducted a clinical trial on sixty patients with untreated hypertension regarding haemodynamic changes following endotracheal Intubation with GlideScope ${ }^{\circledR}$ Video-Laryngoscope (GVL) and Macintosh direct laryngoscope (MDL). They found that haemodynamic fluctuations in patients with uncontrolled hypertension after endotracheal intubation were lower with the GVL than the MDL technique which was to some extent similar to our study. Amini $\mathrm{S}$ et al[6] found that haemodynamic parameters with GVL are better preserved in the first three minutes after intubation than MDL in patients undergoing elective caesarean section and patients were similar regarding intubation time. Murphy LD et al[10] concluded that the KVL was slightly faster than MDL in two of four studied airway scenarios, and had a higher success rate in the difficult cadaver airway scenario. Recent studies also found that video laryngoscope may have advantages over Macintosh laryngoscope in patients having cervical spine immobilisation.[11,12] However, Tempe et al[2] concluded that Video laryngoscopes did not offer any advantage in attenuation of haemodynamic responses in patients with normal airways undergoing CABG and they improve the laryngoscopic views, but prolong the time to intubation. In 2007, Xue et al[13] reported for the first time that there is no difference in haemodynamic responses to tracheal intubation between the GVL and MCL groups in 57 adults, ASA physical status I patients. Kanchi et al[1] also could not demonstrate benefit with the use of Pentax video laryngoscope in terms of obtundation of cardiovascular responses to laryngoscopy and endotracheal intubation in patients with ischaemic heart disease and the time taken for intubation was significantly longer in the Pentax video laryngoscope Group. However, they postulated that if time taken for laryngoscopy and intubation could be reduced they might be able to realise the benefit of video laryngoscope in terms of haemodynamic response.
It is clear from above studies that there are many controversies regarding the advantage of use of video laryngoscope over the direct laryngoscope in terms of haemodynamic changes. Majority of studies have found an increased duration of laryngoscopy and intubation with video laryngoscopes despite adequate visualisation of glottis. The increased duration of laryngoscopy and intubation with video laryngoscopes may account for the failure to demonstrate any haemodynamic benefit with the video laryngoscopes which was consistent with the previous studies.[1,2] Prolonged intubation time with video laryngoscopes in the previous studies could be due to multiple reasons. The video laryngoscope blade occupies larger oral space than Macintosh blade. ${ }^{[1]}$ Enormous experience with direct laryngoscope and less experience with the video laryngoscope may be another reason for quicker intubation with direct laryngoscope as compared with video laryngoscopes. In our study, in some patients, difficulty in navigating the endotracheal tube to the glottis was encountered despite adequate visualisation. However, in most of the patients, this problem with the video laryngoscope was not encountered. In contrast to some other study, our result demonstrated better haemodynamic stability with video laryngoscope may be because of minimum stretching of oropharyngeal soft tissues and comparatively lesser time taken for intubation. Video laryngoscope is a device which needs more expertise for proper utilisation in patients undergoing CABG.

Some limitations are there in this study. First, it was not a double-blind study, since the anaesthesiologist was aware of which instrument to use. Second, patients with MP grade I and II were enrolled in this study while different picture could be there in patients with difficult intubation. Third, in our study we could not measure marker for hormonal stress responses like cortisol, epinephrine, norepinephrine, dopamine, etc. along with haemodynamic parameters.

\section{CONCLUSION}

The King Vision ${ }^{\circledR}$ video laryngoscope causes significantly less haemodynamic responses compared to Macintosh direct laryngoscope in patients undergoing coronary artery bypass grafting surgery. Time taken for laryngoscopy and intubation with KVL is also almost similar like MDL. So, video laryngoscope may be considered as an alternative to direct laryngoscope for patients having coronary artery disease.

\section{REFERENCES}

[1] Kanchi M, Nair HC, Banakal S, et al. Haemodynamic response to endotracheal intubation in coronary artery disease: direct versus video laryngoscopy. Indian J Anaesth 2011;55(3):260-5.

[2] Tempe DK, Chaudhary K, Diwakar A, et al. Comparison of hemodynamic responses to laryngoscopy and intubation with Truview $\mathrm{PCD}^{\mathrm{TM}}$, $\mathrm{McGrath}^{\circledR}$ and Macintosh laryngoscope in patients undergoing coronary artery bypass grafting: a randomized prospective study. Annals of Cardiac Anaesthesia 2016;19(1):68-75.

[3] Khan RM. Video laryngoscopic techniques of tracheal intubation. In: Khan RM. edr. Airway management. $5^{\text {th }}$ edn. Paras Medical Publisher 2015: p. 118. 
[4] Pournajafian AR, Ghodraty MR, Faiz SH, et al. Comparing GlideScope video laryngoscope and Macintosh laryngoscope regarding hemodynamic responses during orotracheal intubation: a randomized controlled trial. Iran Red Crescent Med J 2014;16(4):e12334.

[5] Kahl M, Eberhart LH, Behnke H, et al. Stress response to tracheal intubation in patients undergoing coronary artery surgery: direct laryngoscopy versus an intubating laryngeal mask airway. J Cardiothorac Vasc Anesth 2004;18(3):275-80.

[6] Amini S, Shakib M. Hemodynamic changes following endotracheal intubation in patients undergoing cesarean section with general anesthesia: application of Glidescope ${ }^{\circledR}$ Videolaryngoscope versus direct laryngoscope. Anesth Pain Med 2015;5(2):e21836.

[7] Dashti M, Amini S, Azarfarin R, et al. Hemodynamic changes following endotracheal intubation with Glidescope ${ }^{\circledR}$ video-laryngoscope in patients with untreated hypertension. Res Cardiovasc Med 2014;3(2):e17598.

[8] Aghdaii N, Azarfarin R, Yazdanian F, et al. Cardiovascular responses to orotracheal intubation in patients undergoing coronary artery bypass grafting surgery. Comparing fiberoptic bronchoscopy with direct laryngoscopy. Middle East J Anesthesiol 2010;20(6):833-8.
[9] Ziyaeifard M, Azarfarin R, Massoumi G. A comparison of intraocular pressure and hemodynamic responses to insertion of laryngeal mask airway or endotracheal tube using anesthesia with propofol and remifentanil in cataract surgery. J Res Med Sci 2012;17(6):503-7.

[10] Murphy LD, Kovacs GJ, Reardon PM, et al. Comparison of the king vision video laryngoscope with the macintosh laryngoscope. J Emerg Med 2014;-47(2):239-46.

[11] Liu EH, Goy RW, Tan BH, et al. Tracheal intubation with videolaryngoscopes in patients with cervical spine immobilization: a randomized trial of the Airway Scope and the GlideScope. Br J Anaesth 2009; 103(3):446-51.

[12] Enomoto Y, Asai T, Arai T, et al. Pentax-AWS, a new videolaryngoscope, is more effective than the Macintosh laryngoscope for tracheal intubation in patients with restricted neck movements: a randomized comparative study. Br J Anaesth 2008; 100(4):544-8.

[13] Xue FS, Zhang GH, Li XY, et al. Comparison of haemodynamic responses to orotracheal intubation with GlideScope videolaryngoscope and fibreoptic bronchoscope. Eur J Anaesthesiol 2006;23(6):522-6. 